\title{
A música como fonte de pesquisa no ensino de História na Educação de Jovens e Adultos em Florianópolis: desafios e possibilidades
}

Huerth Moreira*

Matheus Ferreira Machado**

Resumo: O presente artigo pretende contribuir com os debates sobre o ensino de História e o uso da música como fonte histórica na Educação de Jovens e Adultos, tendo como base os desafios e as possibilidades observadasdurante uma experiência de estágio com uma turma de Educação de Jovens e Adultos na Escola Básica Municipal Donícia Maria da Costa em Florianópolis.

Palavras-chave: ensino de história, educação de jovens e adultos, música.

La música como fuente de pesquisa en la enseñanza de la História en la Educación de Jóvenes y Adultos en Florianópolis: desafíos y posibilidades

Resumen: El presente artículo pretende contribuir con los debates sobre la enseñanza de la Historia y el uso de la música como fuente histórica en la Educación de Jóvenes y Adultos, teniendo como base los desafíos y las posibilidades observadas durante una experiencia de práctica con una clase de Educación de Jóvenes y Adultos en la Escuela Básica Municipal Donícia Maria da Costa en Florianópolis.

Palabras-clave: enseñanza de la história, educación de jóvenes y adultos, música.

\section{Introdução}

Este artigo tem o objetivo de discutir as possibilidades e os desafios ao se trabalhar a música como fonte de pesquisa na Educação de Jovens e Adultos (EJA), utilizando como principal objeto nossa experiência de estágio na Escola de Educação Básica Donícia Maria da Costa, bem como os materiais que elaboramos nesse período, como, por exemplo, o relatório de estágio e o projeto de ensino. Sustentando nossa hipótese de mostrar a viabilidade do uso da música como fonte no ensino de história e na construção do conhecimento histórico, reforçamos a necessidade do uso dessa fonte, pois em nossa pesquisa bibliográfica encontramos poucas referências acerca do assunto com aplicação na EJA. Dessa forma, dialogaremos nossa experiência na EJA juntamente com teóricos das áreas de história e da música. Esperamos que o artigo sirva

\footnotetext{
Graduado no Curso de Bacharelado e Licenciatura em História da Universidade Federal de Santa Catarina. E-mail: huerth.moreira@gmail.com.

** Graduando no Curso de Bacharelado e Licenciatura em História da Universidade Federal de Santa Catarina.E-mail: calford00@gmail.com.
} 
80 Polyphonía, v. 29/1, jan./jun. 2018

como referência para outros educadores que desejam explorar novas possibilidades no ensino de história utilizando a música como fonte.

\section{A Escola}

A Escola de Educação Básica Donícia Maria da Costa é mantida pela Prefeitura Municipal de Florianópolis e está localizada no bairro Saco Grande. Atualmente, a instituição atende a 535 estudantes, divididos em 21 turmas. No entanto, nesses números, não estão incluídos os/as estudantes da EJA. Existem duas turmas da EJA, sendo uma do primeiro segmento, que tem aproximadamente 15 estudantes, e a outra do segundo segmento, que tem em torno de 35 estudantes ${ }^{1}$.

Primeiro, é válido ressaltar que nossa experiência de estágio se deu no decorrer do primeiro e segundo semestres do ano de 2015, no qual pudemos vivenciar o cotidiano da sala de aula de uma turma de Educação de Jovens e Adultos (do segundo segmento) da Escola de Educação Básica Donícia Maria da Costa ${ }^{2}$. Nesses semestres, tivemos uma visão mais abrangente sobre como se dá a proposta desta modalidade no município de Florianópolis, no estado de Santa Catarina, que tem como base o ensino pela pesquisa, proporcionando aos/as estudantes autonomia para escolherem o que querem pesquisar, seja um assunto próximo de sua realidade ou não. No período em que observamos a turma em questão, percebemos que muitas pesquisas estavam sendo feitas por curiosidade do/a aluno/a, e não por sugestão ou imposição do corpo docente da escola.

Pensamos que o ensino de História deva ter significado para a vida dos estudantes e atenda suas expectativas. Portanto, é preciso fazer com que os docentes compreendam que história não é somente estudar o passado, mas sim correlacioná-lo com assuntos vigentes no presente, e assim, ter uma visão mais crítica sobre a sociedade. Conforme explicam Fonseca e Silva (2010, p. 24), “ao Ensino de História

\footnotetext{
Primeiro segmento corresponde à fase de alfabetização, e o segundo segmento ao ensino do $5^{\circ}$ ao $9^{\circ}$ ano do ensino fundamental.

2 A professora Joana Vieira Borges, do Departamento de Metodologia de Ensino (MEN) da UFSC, orientou o estágio mencionado durante o segundo semestre de 2015, no qual a experiência descrita foi realizada, e o primeiro semestre de 2016, momento da produção deste texto. No núcleo de EJA em questão fomos supervisionados pela professora-coordenadora Rosemar Ucha Peres.
} 
cabe um papel educativo, formativo, cultural e político, e sua relação com a construção da cidadania perpassa diferentes espaços de produção de saberes históricos.”

\title{
Música x História
}

Embora existam diversas produções bibliográficas sobre a música no ensino história no ensino fundamental e médio, não há muitos textos sobre seus usos especificamente no ensino de história na Educação de Jovens e Adultos. Os textos que tratam do ensino de história - de um modo geral - buscam, principalmente, discutir sobre a construção do conhecimento histórico e como a música pode auxiliar nisso. Um consenso entre os pesquisadores é que se deve diferenciar a formação da informação para evitar a subutilização das fontes. Para Abud (2005, p. 311):

\begin{abstract}
A informação pode ser definida como um pensamento que existe em algum lugar, no tempo e no espaço, e a formação como uma série de ações que apontam para um resultado. No entanto, as linguagens são pouco utilizadas para a formação, que só pode ocorrer quando a informação recebida se relaciona com um conjunto individual de esquemas e de estruturas mentais, que transforma a informação em conhecimento, em novos esquemas e novas estruturas que irão enriquecer o repertório cognitivo ou simbólico daquele que aprende.
\end{abstract}

Como Abud aponta, as linguagens são pouco utilizadas para a formação, e esta proposta - de utilizar a música para a formação e construção do conhecimento histórico - permeou as discussões para a realização do nosso trabalho aplicado na EJA. Alguns conceitos foram adaptados para atender melhor a especificidade da EJA Florianópolis, sendo um deles a escolha de músicas próximas da realidade vivida pelos discentes. Para isso observamos e conversamos com os/as estudantes para entender um pouco mais do universo musical no qual eles/as estavam inseridos.

[...] cabe ao professor, antes de transmitir sua própria cultura musical (no caso, relacionada ao conhecimento histórico), pesquisar o universo musical ao qual o jovem pertence e, daí, encorajar atividades relacionadas com a descoberta e construção de novas formas de conhecimento por meio da música. (ABUD; SILVA; ALVES, 2010, p. 61).

Tendo em mente a proposta da EJA Florianópolis, anteriormente explicitada, adotamos a ideia de trabalhar o uso da fonte para auxiliar nas futuras pesquisas 
realizadas pelos/as estudantes e em seus questionamentos cotidianos, apresentando a música como uma fonte alternativa e tão rica quanto a escrita. Partindo do pressuposto que as letras de música, bem como seus ritmos, se constituem em evidências e registros de um acontecimento, a utilização destes registros colabora na formação de conceitos espontâneos dos/as estudantes e na aproximação entre os/as estudantes e o objeto a ser analisado, neste caso, um período ou acontecimento histórico. Permitem também uma aproximação com os sujeitos que viveram no passado, elaborando assim a compreensão histórica que "vem da forma como sabemos como é que as pessoas viram as coisas, sabendo o que tentaram fazer, sabendo o que sentiram em relação à determinada situação" (ABUD, 2005, p. 316).

\section{A música como fonte histórica}

O trabalho em sala de aula com documentos pode ser pensado como um modo de criar e recriar o que nós somos, formando um sentido original para o ensino da história, vinculados com a formação da identidade dos/as discentes, situados em um determinado contexto histórico. Contudo, é necessário atenção com o uso de fontes nas aulas de história, para que elas não sejam utilizadas como meras ilustrações dos argumentos, decorrente de uma aspiração do/a professor/a em dar veracidade ao relato histórico. Agindo desta forma, perde-se de ensinar os/as estudantes o papel que as fontes assumem no interior de cada geração e de cada uso que delas se faz; seu processo de construção.

De acordo com Chaves (2006), as letras das canções podem ser entendidas como elementos históricos contextualizados, sendo para isso necessário pensar quais as formas mais adequadas de se incorporar a música nas aulas de história, evitando uma utilização superficial.

\section{A música como instrumento para a consciência histórica}

Schmidt e Garcia (2006) alertam para o fato de que o professor precisa se colocar como um investigador social, que busca compreender o mundo conceitual dos/as estudantes para transformá-lo e, nesse processo, o aluno deve ser entendido como 
agente da sua formação - pois ele precisa saber o que já sabe, o que precisa aprender e o que aprendeu de novo. Desse modo, as autoras afirmam que se exige uma abordagem problematizadora dos conteúdos de história, na qual educadores/as e estudantes possam dialogar e propiciar condições de pensar, argumentar e fundamentar suas opiniões por meio de conteúdos escolares socialmente significativos, e que estes possibilitem a formação da consciência histórica, entendida no sentido de orientação, localização e interpretação do passado face às demandas do presente e às perspectivas do futuro, permitindo uma compreensão da História como um processo dinâmico e com várias vozes. Assim como Schmidt e Garcia (2006), Duarte (2011) também afirma que o professor deve atuar como mediador dessa transformação de consciência histórica.

A experiência que marca o indivíduo está, em seu aprender, delimitando-o. Nessa perspectiva, aprender e ensinar supõe a articulação contínua entre aluno e professor que atualiza, a cada passo, experiências que se revertem, invertem ou convergem. Os professores, nesse sentido, seriam todos aprendizes e ensinantes, integrando tempos e espaços nas presenças-ausentes ou ausências-presentes, ou seja, mediadores na transformação da consciência histórica do aluno através ensino de História em sala de aula (DUARTE, 2011, p. 76).

Napolitano (2002) utiliza o binômio “documento-canção" para se referir à música. Concordamos com o autor, pois percebemos a música como um documento histórico e não apenas um arranjo sonoro, e por isso possível de ser explorada em sala de aula no ensino de história. Entendemos que a música é uma fonte pela qual o conhecimento histórico circula e é, também, uma produção cultural, que possui sua historicidade. Logo, apresentá-las como possibilidades cognitivas e fontes de pesquisa para as atividades de formação dos/as estudantes da EJA torna-se objetivo dos docentes. Para o autor,

[...] é fundamental a articulação entre "texto" e "contexto" para que a análise não se veja reduzida, reduzindo a própria importância do objeto analisado. $\mathrm{O}$ grande desafio de todo pesquisador em música popular é mapear as camadas de sentido embutidas numa obra musical, bem como suas formas de inserção na sociedade e na história, evitando, ao mesmo tempo, as simplificações e mecanicismos analíticos que podem deturpar a natureza polissêmica (que possui vários sentidos) e complexa de qualquer documento de natureza estética (NAPOLITANO, 2002, p. 53). 
Deve-se ainda selecionar a música com base em uma escolha metodológica, visto que ela deve servir para instigar o olhar crítico dos discentes e formar suas concepções acerca da História. Sobre essa escolha, Napolitano (2002, p. 65) nos alerta:

\begin{abstract}
Ao escolher uma canção como fonte de pesquisa ou instrumento didático, o professor pode correr o risco de achar que a sua sensibilidade, seu gosto pessoal e sua acuidade crítica podem dar conta da pertinência da seleção para análise. Ledo engano... Trata-se, antes de mais nada, de uma escolha metodológica, cuja única garantia de "acerto" é a sua coerência interna e sua pertinência crítica. Portanto, temos um problema anterior, um procedimento básico para qualquer trabalho deste tipo, em qualquer área do saber. A escolha das canções constitui parte de um "corpo" documental que deve estar coerente com os objetivos da pesquisa ou do curso em questão. Ou seja, ao montar um curso ou um objeto de pesquisa, o profissional deve não só conhecer a sua área de competência geral, operando as articulações necessárias com a historiografia mais abrangente (ex.: História do Brasil, da América etc.), mas procurar o máximo de informações na área específica, da qual "seu" corpo documental emergiu (no caso, a história da música popular brasileira)
\end{abstract}

É necessário tratar a música como documento histórico. Como Abud (2005) aponta, este documento, tratado como histórico, serve como instrumento para desenvolver conceitos históricos e para a formação histórica dos/as estudantes. É importante a utilização de músicas próximas à realidade dos/as estudantes, como já explicitado anteriormente por Abud, Silva e Alves (2010).

A música é também representação de uma realidade e evidência de um fato histórico.

\footnotetext{
Elas são representações, não se constituem num discurso neutro, mas identificam o modo como, em diferentes lugares e em diferentes tempos, uma determinada realidade social é pensada e construída. Serão também instrumentos para a construção de representações sociais dos alunos, evidenciando por meio de múltiplas configurações intelectuais como os diferentes grupos constroem, contraditoriamente, a realidade social. (ABUD, 2005, p. 312).
}

Ao analisar uma música como documento histórico, não devemos esquecer também de analisar sua melodia e contexto histórico de produção. Informações como, autor, data e local de produção são extremamente importantes para uma aproximação entre os/as discentes e a obra a ser analisada.

A organização dos temas e conteúdos a serem trabalhados em sala de aula pode se dar por meio da seleção de uma ou mais músicas, possibilitando novas maneiras de 
aprender História, "desviando-se" de propostas guiadas exclusivamente pela cronologia (ABUD, 2005, p. 315-316). Essa metodologia, além de ser mais atrativa, ajuda na elaboração de conceitos históricos por parte dos/as estudantes. Desta forma, a música torna-se objeto de estudo, permitindo uma aproximação do/a aluno/a com o tempo histórico estudado - através do autor, local, entre outros.

Ao pensar a metodologia acima exposta para a Educação de Jovens e Adultos, em específico, é possível superar o modelo racionalista de interpretação histórica muito presente no nosso sistema de educação - que pressupõe apenas uma interpretação do passado histórico, não havendo possibilidade de uma história de múltiplas perspectivas.

\section{A música na Educação de Jovens e Adultos: relato da experiência de estágio}

Nossa oficina, intitulada de "A música como documento histórico", aconteceu no dia 23 de outubro, uma sexta-feira, durante todo o período de aula - das $19 \mathrm{~h}$ às $21 \mathrm{~h} 45 \mathrm{~min}$. O objetivo geral da nossa oficina era fazer com que a turma reconhecesse que a música é uma fonte para a investigação histórica, além de um recurso para a interpretação do passado e do tempo presente, sobretudo concernente à formação da identidade do indivíduo. É válido ressaltar que nossa oficina teve como uma das bases a observação feita no estágio. Nosso projeto foi sendo moldado conforme as demandas e particularidades apresentadas pelos/as estudantes e por isso era extremamente importante uma maior aproximação com estes discentes. Em nenhum momento deixamos de refletir sobre como a nossa oficina poderia impactar na vida destes/as estudantes, já que estes eram os principais agentes da oficina. De nada adiantaria uma atividade que estivesse distante da realidade ou não trouxesse reflexões acerca do dia a dia - escolar ou não - destes estudantes. Também é importante destacar que estas observações não foram feitas somente em sala de aula. As conversas informais pelos corredores e refeitório também foram significativas, justamente por compreendermos que estes espaços eram extensões da sala de aula e não deveriam ser desconsiderados.

Tendo conhecimento destes fatos, a discussão sobre identidade se mostrou necessária frente à grande hierarquização cultural presente na fala dos/as estudantes. A música é "[...] produto de longas e incontáveis vivências coletivas e individuais com as 
experiências de civilizações diversas ao longo da história” (DUARTE, 2011, p. 11), sendo assim uma forma de identificação cultural. Por isso, sugerimos o diálogo entre história, música e identidade, tendo como um dos objetivos explicar através das músicas escolhidas a formação cultural de alguns grupos que permeiam nossa sociedade e desconstruir a concepção de hierarquização cultural. Um ensinamento que ultrapassa os muros da escola e se mostra importante também no meio cívico, como sugere a proposta da EJA Florianópolis.

Dessa forma, começamos questionando os/as estudantes a respeito de seus entendimentos sobre o que são as fontes e os documentos históricos, com a intenção de verificar os saberes prévios. Nossa participação neste momento da oficina se deu de maneira instigadora, visando sempre dar espaço para os/as estudantes apresentarem suas ideias e conceitos, e atuando, também, como moderadores do debate. Surgiram algumas opiniões que, de certa maneira, ajudaram a turma a começar a fazer posicionamentos sobre o assunto. Em seguida, trabalhamos uma definição de fonte já pronta, presente nos trabalhos de Maria Auxiliadora Schmidt e Marlene Cainelli. Notamos que esta ação não teve grande destaque, uma vez que era uma definição com linguagem acadêmica, que carecia de uma mediação, e, notando isso, explicamos utilizando exemplos e atuando como mediadores entre os estudantes e o conhecimento, o que se mostrou mais proveitoso. A partir daí, ao percebermos a dinâmica da turma, procuramos a compreensão e o debate por meio de perguntas instigadoras, que repercutiram em mais comentários e opiniões do que anteriormente. Ao terminarmos essa etapa de identificação de fonte histórica, verificamos que a turma conseguiu compreender que a música é um documento possível para pesquisa.

O tempo seguinte foi reservado para que a turma pudesse reconhecer e identificar os gêneros musicais e também o entendimento delas através da contextualização que fizemos em conjunto. A escolha das canções utilizadas se deu com base no convívio diário e análise dos gostos musicais dos/as estudantes. Para tanto selecionamos três músicas: "Todo camburão tem um pouco de navio negreiro" (O Rappa), "Se o Leonardo dá vinte" (Bezerra da Silva) e "Diário de um detento" (Racionais MC's). Iniciamos esse momento projetando as letras e, em seguida, realizamos as audições. Após ouvirmos as músicas, dividimos a turma em três grupos. Cada grupo ficou responsável por responder um questionário com perguntas que 
viessem a proporcionar uma reflexão sobre cada música. As perguntas incluídas neste questionário foram as seguintes:

1. Qual o gênero musical (exemplo: funk, pop, reggae) desta música?

2. Qual o artista ou grupo musical que canta esta música?

3. Em que época (ano/década) essa música foi feita?

4. A letra da música tem algum(s) tema(s)? Se sim, qual (quais)?

5. Quais palavras mais te chamam atenção na letra da música e quais palavras você acha que explicam melhor a música?

6. O que esta música me informa?

7. A música procura expor a realidade? Se "sim", de que forma?

8. Para quem a letra dessa música foi feita? Ela procura atingir um grupo de pessoas em particular?

Esta atividade ocasionou um grande debate a respeito das letras das músicas e todo o seu contexto histórico, que foi de grande importância para nós naquele momento, pois acreditamos que este era um dos nossos principais objetivos com a oficina. Ao término da nossa apresentação propusemos uma HPE (Hora de Produção Externa) ${ }^{3}$ com o intuito de contribuir para a prática dos saberes desenvolvidos durante a oficina. Nesta HPE, os/as estudantes teriam que selecionar uma música que tivesse a ver com suas respectivas pesquisas ${ }^{4}$, ou de sua preferência, e realizar uma análise crítica conforme a que foi feita na oficina.

Com esta experiência acreditamos e defendemos que todo esse trabalho desenvolvido pretendeu contribuir não apenas para a análise de uma determinada

3 Horas de Produção Externa (HPE) ou Horas Não Presenciais (HNP) são aquelas previamente planejadas no núcleo com professores/as e estudantes e que são realizadas fora do horário escolar. A função é facilitar a percepção de que se pode aprender em todos os momentos, e não deve-se confundí-las com a prática do "deveres de casa". Cf. PREFEITURA MUNICIPAL DE FLORIANÓPOLIS. SECRETARIA MUNICIPAL DE EDUCAÇÃO. Estrutura, Funcionamento, Fundamentação e Prática na Educação de Jovens e Adultos EJA. 2008 (Disponível em: http://www.pmf.sc.gov.br/arquivos/arquivos/pdf/22_02_2010_9.36.57.04162e08d6cd8876612adc5ada375bd5.pdf Acesso em: 05 abr. 2017.

4 A prática pedagógica da EJA Florianópolis orienta-se pela pesquisa como princípio educativo. Assume-se, portanto, o caráter da pesquisa como meio de desenvolvimento de potencialidades necessárias à realização humana. Cf. SECRETARIA MUNICIPAL DE EDUCAÇÃO. DEPARTAMENTO DE EDUCAÇÃO DE JOVENS E ADULTOS. Diretrizes para a implantação do plano de curso da educação de jovens e adultos da rede municipal de ensino de Florianópolis. Florianópolis, DEJA, 2012. Disponível em: http://www.pmf.sc.gov.br/arquivos/arquivos/doc/16_02_2012_17.58.23.4c2366919c16ff6fa8c19f510fbf1dbb.doc . Acesso em: 05 abr. 2017. 
música, como o ocorrido na oficina, mas para que os/as estudantes da EJA pudessem levar essa prática para suas vidas e, ao ouvirem uma música fora da sala de aula, conseguissem analisá-las de maneira questionadora, interrogando e contextualizando sua letra, seu ritmo e o contexto no qual ela se insere.

\section{Resultados e discussões}

Percebemos através da experiência que tivemos na turma na qual estagiamos que a música, usada como fonte histórica, atraiu a atenção dos/as estudantes pela proximidade e convivência diária com as canções. Observamos que após nossa explicação acerca do tema os/as estudantes ampliaram suas visões e conseguiram pensar a música para além da sonoridade, fazendo o exercício de refletir sobre sua letra e o que ela tem para passar como mensagem principal. Como Bittencourt (2011, p. 379) expõe: "Existe enorme diferença entre ouvir música e pensar a música".

Ao fazermos uma análise das avaliações - aplicadas como Hora de Produção Extra (HPE) - constatamos que os/as estudantes conseguiram compreender a proposta da nossa oficina. Essas HPE's foram distribuídas ao final da oficina como um dever de casa e recolhidas uma semana depois da aplicação para uma avaliação. O objetivo destas HPE's era perceber se os/as estudantes haviam compreendido de fato o que fora proposto. Embora não existisse uma única resposta correta para as perguntas, notou-se coerência e um esforço para se extrair o máximo de elementos das canções analisadas. Foi possível perceber também o universo musical no qual estavam inseridos os/as estudantes, visto que as músicas selecionadas para responder o questionário foram escolhidas por cada um/a individualmente.

No que tange ao universo musical do/a estudante, concordamos com Abud, Silva e Alves (2010), ao também afirmarmos que o professor deve se esforçar para trazer músicas próximas da vivência da turma. Esta aproximação torna a música trabalhada muito mais significativa, visto que aborda temas presentes na vida destes indivíduos, ou, simplesmente, lhes é familiar. Para uma proposta como a da EJA/Fpolis e para uma primeira aproximação, não seria correto apresentarmos músicas distantes do cotidiano vivido pelos/as estudantes. Seria apenas mais uma canção que nunca lhes diz respeito e, portanto, não seria significativo para estes jovens e adultos. 
Como Bittencourt (2011) afirma, há uma facilidade em usar a música para despertar o interesse dos/as estudantes e um problema em transformá-la em objeto de investigação. Como deixar a música interessante ao mesmo tempo em que a transformamos em objeto de investigação? Em se tratando da EJA e da experiência que tivemos antes de elaborarmos a oficina, o desafio estava em manter o conteúdo interessante e atrativo sem desvalorizar ou até mesmo subutilizar a nossa proposta de análise de músicas como fonte de pesquisa. Problema este que permeou as nossas discussões para estruturarmos a nossa oficina. Era preciso fazer com que os/as estudantes compreendessem que a música é objeto passível de investigação e é mais do que apenas ritmos e sons, é também produto de vivências coletivas e individuais (DUARTE, 2011), produzidas em um determinado contexto histórico. Para a nossa surpresa, não foi difícil fazer com que eles/as tivessem essa compreensão, o que facilitou e ajudou no andamento da oficina.

Após realizarmos uma revisão bibliográfica, constatamos que nosso projeto de estágio contribuiu, também, para uma nova abordagem acerca do assunto, pois, de todos os autores e autoras que lemos e tivemos acesso, não obtivemos experiências em relação à utilização da música como fonte histórica na EJA. Sendo assim, acreditamos que cumprimos com o nosso objetivo de propor uma nova visão sobre a música como fonte histórica para aqueles/as estudantes e habilitá-los para seguir utilizando canções como fonte de pesquisa e analisando-as de forma crítica em seu cotidiano.

Infelizmente, devido ao fato de não termos frequentarmos o núcleo por muito tempo após a realização da nossa oficina, não pudemos verificar se os/as estudantes continuaram utilizando a música como fonte para suas pesquisas.

\section{Considerações finais}

Ao utilizar a música como fonte histórica na EJA é importante que o docente conheça os/as estudantes e os/as entenda como sujeitos em sua diversidade. De acordo com Haddad (2002), os estudos sobre a EJA tendem a massificar as/os estudantes, analisando-as/os como um segmento homogêneo. Entretanto, a escola e os sujeitos que a constituem precisam ser conhecidos enquanto universos de sociabilidade e de práticas culturais diversas. Como coloca Sposito (2001, p. 98): 
[...] no espaço escolar, ora trabalhamos com a categoria de aluno ou estudante, ora recuperamos a categoria de trabalhador, para designar um tipo de relação derivado da classe social. Assim, outras dimensões como o gênero - homens ou mulheres - ou a geração - crianças, jovens e adultos desaparecem.

Deste modo, ao pensar o uso da música em uma sala da EJA, deve-se ter em mente que os/as/ estudantes tem interesses musicais distintos, exigindo do/a docente a apresentação de diversos gêneros musicais para o segmento da Educação de Jovens e Adultos.

Em contrapartida ao pensamento de Haddad (2002), Oliveira (1999, p. 59) defende que a EJA "não diz respeito a reflexões e ações educativas dirigidas a quaisquer jovens e adultos, mas delimita um determinado grupo de pessoas relativamente homogêneo no interior da diversidade de grupos culturais da sociedade contemporânea”. Embora sejam concepções opostas, entendemos que Oliveira (1999) vê o grupo como "relativamente homogêneo" - como ela mesma nomeia - pois os sujeitos da EJA se encaixam em três traços culturais comuns: a condição de nãocrianças; a condição de excluídas/os da escolar regular; e a condição de membros de determinados grupos culturais. Concordamos com ambos autores, pois percebemos os/as estudantes da EJA como heterogêneos entre si, visto que são pessoas com interesses diferentes; mas os percebemos como "relativamente homogêneos" pelos motivos supracitados por Oliveira (2009).

Pensar a música como fonte histórica na Educação de Jovens e Adultos é um assunto que merece um aprofundamento, visto a escassez de bibliografias referentes a este segmento. Reiteramos que a música deve ser utilizada na sala de aula como uma fonte para adquirir o conhecimento histórico, ou seja, ela deve ser usada de forma a ser questionada e pensada pelos/as estudantes, não sendo estes somente ouvintes.

Por fim, corroboramos com Napolitano (2002, p. 7) quando diz que "o Brasil, sem dúvida uma das grandes usinas sonoras do planeta, é um lugar privilegiado não apenas para ouvir música, mas também para pensar a música." Sendo assim, ao utilizar a música em sala de aula como fonte, ela não deve ser utilizada apenas como confirmação do conhecimento já adquirido, mas de forma a permitir aos estudantes a apropriação do conhecimento histórico. 


\section{Referências}

ABUD, Katia Maria. Registro e representação do cotidiano. Cad. Cedes, Campinas, vol. 25, n. 67, p. 309-317, set./dez. 2005.

ABUD, Katia Maria; SILVA, André Chaves de Melo; ALVES, Ronaldo Cardoso. Letras de música e aprendizagem de História. In: . Ensino de história. São Paulo: Cengage Learning, 2010. p.59-79.

BITTENCOURT, Circe Maria Fernandes. Ensino de História: fundamentos e métodos. $4^{a}$ edição. São Paulo: Cortez, 2011.

CHAVES, Edilson. Música Caipira em Aulas de História: questões e possibilidades. Dissertação de Mestrado. UFPR, 2006. Disponível em: <http://www.ppge.ufpr.br/teses/M06_chaves.pdf >. Acesso em: 15 abr. 2016.

DUARTE, Milton Joeri Fernandes. A música e a construção do conhecimento histórico em aula. Tese de Doutorado. USP, 2011, 160p. Disponível em: $<$ http://www.teses.usp.br/teses/disponiveis/48/48134/tde-04072011-144004/fr.php〉. Acesso em: 15 abr. 2016.

FONSECA, Selva Guimarães; SILVA, Marcos Antônio da. Ensino de História hoje: errâncias, conquistas e perdas. Revista Brasileira de História, São Paulo, v. 31, n. 60, p. 13-33, 2010. Disponível em: http://www.scielo.br/pdf/rbh/v30n60/a02v3060.pdf . Acesso em: 20 set. 2015.

HADDAD, Sérgio. Educação de Jovens Adultos no Brasil (1986-1998). Brasília: MEC/INEP/COMPED, 2002.

NAPOLITANO, Marcos. História \& Música: História cultural da música popular. Belo Horizonte: Editora Autêntica, 2002.

OLIVEIRA, Marta Kohl de. Jovens e adultos como sujeitos de conhecimento e aprendizagem. Revista Brasileira de Educação. Set./Out./Nov./Dez. 1999, n. 12, p. 59-73. Disponível em: http://www.pead.faced.ufrgs.br/sites/publico/eixo7/eja_antigo2/jovens_e_adultos_como_sujeitos_de _conhecimento_e_aprendizagem.pdf. Acesso em: 14 abr. 2016.

PEREIRA, Nilton Mullet; SEFFNER, Fernando. O que pode o ensino de história? Sobre o uso de fontes na sala da aula. Anos 90, Porto Alegre, v. 15, n. 28, p. 113-128, 2008. Disponível em: http://www.ufrgs.br/lhiste/o-que-pode-o-ensino-de-historia-sobre-o-usode-fontes-na-sala-de-aula/ . Acesso em: 19 set. 2015.

PREFEITURA DE FLORIANÓPOLIS. SECRETARIA MUNICIPAL DE EDUCAÇÃO. Estrutura, Funcionamento, Fundamentação e Prática na Educação de Jovens e Adultos EJA. 2008 (Disponível em: http://www.pmf.sc.gov.br/arquivos/arquivos/pdf/22_02_2010_9.36.57.04162e08d6cd8876612adc5ada3 75bd5.pdf Acesso em: 05 abr. 2017. 
PREFEITURA DE FLORIANÓPOLIS. SECRETARIA MUNICIPAL DE EDUCAÇÃO. DEPARTAMENTO DE EDUCAÇÃO DE JOVENS E ADULTOS. Diretrizes para a implantação do plano de curso da educação de jovens e adultos da rede municipal de ensino de Florianópolis. Florianópolis, DEJA, 2012. Disponível em: http://www.pmf.sc.gov.br/arquivos/arquivos/doc/16_02_2012_17.58.23.4c2366919c16f f6fa8c19f510fbf1dbb.doc. Acesso em: 05 abr. 2017.

SCHMIDT, Maria Auxiliadora; GARCIA, Tânia Maria Braga. Pesquisas em Educação Histórica. In: Educar. Curitiba, Especial, 2006, p. 11-31. Disponível em: $<$ https://moodle.ufsc.br/pluginfile.php/558564/mod_resource/content/0/Artigo_Pesquisa s_em_Educacao_Historica.pdf $>$. Acesso em: 16 abr. 2016.

SPOSITO, Marília Pontes. Juventude: crise, identidade e escola. In: DAYNELL, Juarez (Org.). Múltiplos olhares sobre educação e cultura. Belo Horizonte: Editora da UFMG, $2^{\mathrm{a}}$ ed., 2001, p. 96-104.

Recebido em: 27 abr. 2018. Aceito em: 28 maio 2018. 